\title{
The role of lysosomes in iron metabolism and recycling
}

Tino Kurz, John W. Eaton and Ulf Brunk

\section{Linköping University Post Print}

N.B.: When citing this work, cite the original article.

Original Publication:

Tino Kurz, John W. Eaton and Ulf Brunk, The role of lysosomes in iron metabolism and recycling, 2011, International Journal of Biochemistry and Cell Biology, (43), 12, 1686-1697. http://dx.doi.org/10.1016/j.biocel.2011.08.016

Copyright: Elsevier http://www.elsevier.com/

Postprint available at: Linköping University Electronic Press http://urn.kb.se/resolve?urn=urn:nbn:se:liu:diva-73315 
Biology

Elsevier Editorial System(tm) for The International Journal of Biochemistry \& Cell Manuscript Draft

Manuscript Number: BC-D-11-00291R1

Title: The role of lysosomes in iron metabolism and recycling

Article Type: Review

Keywords: Autophagy; Iron; Iron-binding proteins; Lipofuscin; Lysosomes

Corresponding Author: Dr. Tino Kurz, Ph.D.

Corresponding Author's Institution: University of Linkoping

First Author: Tino Kurz, Ph.D.

Order of Authors: Tino Kurz, Ph.D.; John W Eaton; Ulf T. Brunk 


\title{
Invited Review
}

\section{The role of lysosomes in iron metabolism and recycling}

\author{
TINO KURZ1* ${ }^{*}$, JOHN W. EATON², and ULF T. BRUNK¹
}

${ }^{1}$ Division of Pharmacology, Faculty of Health Sciences, Linköping University, 58185

Linköping, SWEDEN. ${ }^{2}$ James Graham Brown Cancer Center, University of Louisville, Louisville, KY 40202, USA.

Running head: Kurz et al. - Lysosomes and iron metabolism

Keywords (5): Autophagy; Iron; Iron-binding proteins; Lipofuscin; Lysosomes.

Abbreviations:

ATG, autophagy related genes; CMA, chaperone mediated autophagy; DFO, desferrioxamine; DMT1, divalent metal transporter 1; Hmox 1, heme oxygenase 1; IRE, iron-responsive element; ISC, iron sulfur cluster; LDL, low density lipoprotein; LMP, lysosomal membrane permeabilisation; MP, mannose-6-phosphate; NTBI, nontransferrin-bound iron; ROS, reactive oxygen species; RPE, retinal pigment epithelium; SOD, superoxide dismutase; Tf, transferrin; TfR1, transferrin receptor 1 ; TGN, trans-Golgi network; SIH, salicyl isonicotinoyl hydrazone.

* To whom correspondence should be sent at:

Linköping University

Division of Pharmacology, Faculty of Health Sciences

58185 Linköping, SWEDEN

E-mail: tino.kurz@liu.se

Tel: +46-10-1038968

Fax: +46-13-149106 


\section{LIST OF CONTENTS}

I. INTRODUCTION

II. SYSTEMIC IRON HOMEOSTASIS

III. REGULATION OF CELLULAR IRON UPTAKE

IV. MITOCHONDRIAL UPTAKE AND METABOLISM OF IRON

V. THE ROLE OF LYSOSOMES IN INTRACELLULAR IRON METABOLISM

VI. LYSOSOMAL ACCUMULATION OF LIPOFUSCIN AND ITS INFLUENCE ON AUTOPHAGY AND AGEING

VII. LYSOSOMAL IRON AND IONIZING IRRADIATION

VIII. MACROPHAGE LYSOSOMAL IRON AND ATHEROSCLEROSIS

IX. LYSOSMAL IRON AND DIABETES

X. LYSOSOMAL IRON AND NEURODEGENERATIVE DISEASES

XI. CONCLUSIONS AND PERSPECTIVES FOR THE FUTURE

XII. REFERENCES

XIII. FIGURE LEGENDS 


\section{ABSTRACT}

Iron is the most abundant transition metal in the earth's crust. It cycles easily between ferric (oxidized; $\mathrm{Fe}(\mathrm{III})$ ) and ferrous (reduced; $\mathrm{Fe}(\mathrm{II})$ ) and readily forms complexes with oxygen, making this metal a central player in respiration and related redox processes. However, 'loose' iron, not within heme or iron-sulfur cluster proteins, can be destructively redox-active, causing damage to almost all cellular components, killing both cells and organisms. This may explain why iron is so carefully handled by aerobic organisms. Iron uptake from the environment is carefully limited and carried out by specialized iron transport mechanisms. One reason that iron uptake is tightly controlled is that most organisms and cells cannot efficiently excrete excess iron. When even small amounts of intracellular free iron occur, most of it is safely stored in a non-redox-active form in ferritins. Within nucleated cells, iron is constantly being recycled from aged iron-rich organelles such as mitochondria and used for construction of new organelles. Much of this recycling occurs within the lysosome, an acidic digestive organelle. Because of this, most lysosomes contain relatively large amounts of redox-active iron and are therefore unusually susceptible to oxidant-mediated destabilization or rupture. In many cell types, iron transit through the lysosomal compartment can be remarkably brisk. However, conditions adversely affecting lysosomal iron handling (or oxidant stress) can contribute to a variety of acute and chronic diseases. These considerations make normal and abnormal lysosomal handling of iron central to the understanding and, perhaps, therapy of a wide range of diseases. 


\section{INTRODUCTION}

The transition metal iron is the most abundant metal on the earth. Its capacity to swiftly change between different valences, mainly Fe(II) and Fe(III), makes it an excellent electron transporter and it is found in a large number of essential enzymes and other macromolecules. Iron is, however, also associated with harmful processes, many of which take place inside the lysosomal compartment where iron occurs in low mass redox-active form, creating Fenton-type reactions with hydrogen peroxide that may diffuse from the cytosol (vide infra). As a consequence, lysosomes may be destabilized or accumulate the age pigment lipofuscin with secondary depression of autophagic capacity (Kurz et al., 2010, Terman et al., 2010).

Most metabolically active iron exists within hemoglobin, myoglobin and cytochromes. In mitochondria, iron is a vital part of the electron-transporting complexes and in the cytoplasm it is a prosthetic group of a number of enzymes that drive redox reactions. Since humans lack mechanisms for iron elimination, except menstrual bleeding and removal of apoptotic enterocytes and some macrophages by defecation, iron uptake is strictly regulated (vide infra). Nevertheless, over time, iron as well as some other heavy metals, accumulate, especially in postmitotic cells such as neurons and myocardial cells (Brun and Brunk, 1973, Brunk et al., 1992, Double et al., 2008). This accumulation is largely associated with the age pigment lipofuscin that forms and remains within the lysomal compartment (vide infra). Whether or not such iron-accumulation is linked to any pathological processes is not clear, but it is of interest to note that disturbances in iron metabolism have been coupled to several neurodegenerative diseases such as Alzheimer's, Parkinson's and Huntington's diseases and Friedreich's ataxia. 
As mentioned above, iron is a transition metal able to transport electrons and its facile interconversion from Fe(II) to Fe(III) makes it hazardous if present in free form. $\mathrm{Fe}(\mathrm{II})$ can react with oxygen $\left(\mathrm{O}_{2}\right)$ to form superoxide $\left(\mathrm{O}_{2}{ }^{\bullet-}\right)$. More importantly, Fe(II) can also homolytically cleave hydrogen peroxide $\left(\mathrm{H}_{2} \mathrm{O}_{2}\right)$ yielding hydroxyl radicals $\left(\mathrm{HO}^{\bullet}\right)$ and hydroxyl ions $\left(\mathrm{OH}^{-}\right) . \mathrm{HO} \bullet$ is a particularly aggressive, oxidative and short-lived species (half-life $\sim 10^{-9} \mathrm{sec}$ ) that reacts directly where it is formed without having the time to diffuse. Therefore, antioxidants that are supposed to react with and detoxify $\mathrm{HO}^{\bullet}$ must be present in tissues in enormous and non-physiological concentrations to be able to significantly protect against this radical. Consequently, many substances considered to be effective antioxidants are most probably not at all scavengers of $\mathrm{HO}^{\bullet}$, but are either chelators that prevent iron from reacting with hydrogen peroxide or molecules like $\mathrm{N}$-acetyl cysteine that enhance the concentration of glutathione (GSH) that in turn helps glutathione peroxidase to degrade hydrogen peroxide. Interestingly, many natural antioxidants that are found in grapes, blueberries, tea and other plants are polyphenols and powerful ironchelators (Hatcher et al., 2009, Lopes et al., 1999, Mandel et al., 2006).

Superoxide is not a particularly powerful oxidant but rather acts as a reducing agent. By itself it is not very reactive but has the capacity to reduce Fe(III) to Fe(II), thereby initiating the production of the much more destructive HO ${ }^{\bullet}$. Since superoxide dismutase (SOD) is an enzyme that occurs in large amounts in the cytosol, mitochondria and extra-cellularly, we can deduce that superoxide is indeed toxic and in need of being eliminated before it manages to reduce unreactive Fe(III) to reactive Fe(II). This concept is supported by the fact that although $\mathrm{O}_{2}{ }^{\bullet}$ - spontaneously dismutates at a high rate $\left(5 \times 10^{5} \mathrm{M}^{-1} \mathrm{~s}^{-1}\right.$ at $\left.\mathrm{pH} 7.0\right)$, the reaction is accelerated up to $1.5 \times 10^{9} \mathrm{M}^{-1} \mathrm{~s}^{-1}$ by SOD (Halliwell and Gutteridge, 2007a). 
Considering these realities, it is understandable that evolution has led to the development of a range of complicated measures that allow iron to be taken up from the food in a very regulated way, transported in bound non-redox-active form and delivered, sorted and stored in cells probably without ever being redox-active. Actually, recent evidence supports the idea that only when liberated within the lysosomal compartment following autophagic degradation of iron-containing macromolecules does some iron exist in redox-active form for a short period of time before being recycled or stored. This danger is lessened, but not eliminated, by intralysosomal mechanisms that keep low mass iron in bound form (vide infra).

\section{SYSTEMIC IRON HOMEOSTASIS}

The total body iron of a healthy human is typically about $50 \mathrm{mg} / \mathrm{kg}$, most of which is in hemoglobin and myoglobin within erythrocytes and muscle cells, respectively (Munoz et al., 2009). Since humans lack an effective iron-excreting mechanism (McCance and Widdowson, 1938), body iron has to be tightly regulated by strictly controlled uptake from the food, which in turn requires effective reutilization following degradation of iron-containing macromolecules. Only $0.5-2 \mathrm{mg} /$ day of iron is absorbed by the enterocytes of the upper part of the small bowel from where it is transported by the blood to cells in need of a supply (Munoz et al., 2009, Sharp and Srai, 2007). Aged erythrocytes (mean life span 120 days) are phagocytosed by macrophages and degraded within their lysosomal compartment. Iron is then excreted to the blood, bound by transferrin and transported away for reutilization (Dunn et al., 2007). Dietary non-heme iron is not as bioavailable and has to be reduced by ferrireductases before it can pass the apical enterocyte membrane. It is then transported into the cytoplasm by the divalent metal transporter 1 (DMT1) 
(Mims and Prchal, 2005). Heme-iron, however, is easily absorbed by a receptormediated mechanism using the heme-carrier protein-1. In the enterocyte, iron is liberated by heme oxygenase 1 (Hmox 1) (Dunn et al., 2007). Iron is then transported away from the basolateral membrane of the enterocyte and from macrophages, by ferroportin 1, which is expressed in all iron-exporting cells and plays a critical role in the regulation of iron-export to the bloodstream (Donovan et al., 2005, Troadec et al., 2010).

A newly identified protein, hepcidin, is produced by the liver in response to high intracellular iron levels and excreted into the circulation where it interacts with ferroportin 1 on the surface of iron exporting cells (enterocytes, macrophages and hepatocytes) and causes the complex to be endocytosed and degraded. This feedback mechanism is important for the regulation of circulating iron by preventing iron export (Knutson et al., 2005, Nemeth et al., 2006). Exactly how hepatocyte iron regulates the production of hepcidin is presently not known.

Following its release into the bloodstream from enterocytes and macrophages, iron binds to transferrin (Tf), an abundant plasma glycoprotein able to bind two atoms of iron with very high affinity (Aisen et al., 1978, Morgan, 1981). Consequently, little or no free and potentially toxic iron is in circulation (Anderson and Vulpe, 2009). Circulating Tf-Fe binds to the plasma membrane transferrin receptor 1 (TfR1) and the complex is endocytosed (Richardson and Ponka, 1997). In the slightly acidic environment of late endosomes, iron is released and transported into the cytoplasmic pool of labile (chelatable) iron by DMT1. Whether or not iron in this pool is redox-active is unknown, neither is it known in which molecular form iron exists within this transient pool before it is incorporated and stored in ferritin or delivered to the mitochondria or elsewhere for synthesis of iron-sulfur complexes, 
heme and iron-containing enzymes. Recent studies on erythroid cells have given results that challenge the existence of a labile pool of iron in at least these particular cells and point to a docking process between late endosomes and mitochondria (Sheftel et al., 2007). Further research is needed to clarify the exact mechanisms of iron transport from late endosomes to ferritin or places of synthesis for ironcontaining macromolecules, mainly in the mitochondria.

Storage of excess iron in ferritin is essential to prevent iron-mediated oxidative processes and ferritin is therefore a most important anti-oxidant (Arosio et al., 2009, Balla et al., 1992, Balla et al., 1993). Ferritin is a high molecular weight 24-mer consisting of heavy (H-ferritin) and light (L-ferritin) subunits (Harrison and Arosio, 1996). The ferroxidase activity of the H-chain is responsible for converting Fe(II) to Fe(III) and then together with the L-form for its storage as a ferric oxohydroxide mineral (Arosio et al., 2009). The final complex is a $12 \mathrm{~nm}$ wide structure with an 8 $\mathrm{nm}$ wide core that may harbor up to 4,500 atoms of iron in a bioavailable but safe form (Chasteen and Harrison, 1999).

Recently, the presence of ferritin has been demonstrated also in mitochondria and in the nucleus. Interestingly, mitochondrial ferritin is mainly comprised of H-chains (Levi et al., 2001, Santambrogio et al., 2007) which might indicate that the main function of this particular ferritin is to ensure that no Fe(II) is present, which in light of the substantial production of superoxide in mitochondria would make sense and prevent Fenton-type reactions. An overview of selected proteins and their function in iron metabolism is presented in Table 1. 


\section{REGULATION OF CELLULAR IRON UPTAKE}

The Tf-TfR1 complex is re-circulated to the cell surface, where the neutral $\mathrm{pH}$ causes the iron-free $\mathrm{Tf}$ to dissociate from the receptor and be returned to the circulation (Gunshin et al., 1997, Ponka et al., 1998). Recently, a number of other iron-uptake mechanisms have been identified, especially for hepatocytes, which express transferrin receptor 2 (TfR2) that is a homolog to TfR1 (Graham et al., 2008, Kawabata et al., 2001, West et al., 2000). The affinity between the latter receptor and iron is, however, much lower than for TfR1 and its role in iron-uptake is not fully established.

In iron over-load conditions, such as thalassemia and haemochromatosis, when the iron-binding capacity of $\mathrm{Tf}$ is saturated, some circulating non-transferrin-bound iron (NTBI) can be detected (Esposito et al., 2003, Loreal et al., 2000). The increased NTBI may result in hemosiderosis of the liver, heart and insulin-producing $\beta$-cells (Anderson and Vulpe, 2009).

The iron regulatory proteins 1 and 2 (IRP1 and IRP2) control the uptake and storage of iron at the cellular level by interacting at the translational level with ironresponsive elements (IREs) on RNA transcripts that code for the $\mathrm{H}$ - and L-ferritin subunits, TfR1, DMT1, mitochondrial aconitase and 5-aminolevulinate synthase (Hentze et al., 2010, Rouault, 2006). Depending on their degree of iron binding, IRPs attach themselves to IREs and thereby prevent or stabilize translation of the above proteins that regulate uptake, storage, transport and metabolism of intracellular iron. As an example: in the presence of sufficient iron, formation of TfR1 is suppressed and ferritin is produced, while the opposite happens when cellular iron is low. The result is a strict control of iron uptake and storage (Hentze and Kuhn, 1996, Rouault and 
Klausner, 1997). The details of this sophisticated regulation, still not known in all particulars, are beyond the scope of this review.

\section{MITOCHONDRIAL UPTAKE AND METABOLISM OF IRON}

Mitochondria are central for iron metabolism and most iron sulfur clusters (ISC) and all heme molecules are synthesized inside the matrix of mitochondria (Muhlenhoff and Lill, 2000, Ponka, 1997). However, the details of how iron is targeted to these organelles or how heme is exported to the cytosol remain unclear. The recently detected proteins mitoferrin 1 and mitoferrin 2 might act as iron-transporters over the inner mitochondrial membranes (Paradkar et al., 2009, Shaw et al., 2006), although they cannot be the only transporters involved because their deletion is not lethal. Since mitochondria are the main cellular producers of superoxide and hydrogen peroxide, one has to anticipate that mitochondrial iron is predominantly kept in a non-redox-active form since otherwise fulminant production of hydroxyl radicals would result. In cells with high metabolic activity, such as cardiomyocytes and neurons, a mitochondrial ferritin with high homology to H-ferritin may function as an antioxidant by oxidizing existing Fe(II) and then keeping it bound (Campanella et al., 2009, Santambrogio et al., 2007).

It has recently been found that mitochondrial iron increases with age, leading to suggestions that enhanced availability of redox-active iron in mitochondria might be a causative factor in the decline of mitochondrial performance that is found in aged organisms and secondary to iron-overload (Gao et al., 2010, Xu et al., 2010). 


\section{THE ROLE OF LYSOSOMES IN INTRACELLULAR IRON METABOLISM}

The lysosomal compartment is crucial for cell maintenance and has a variety of important functions, including participation in endocytic uptake of materials from the outside and autophagic degradation of damaged mitochondria and other organelles as well as numerous, mostly long-lived, proteins. Consequently, lysosomes exist in all kinds of plant and animal cells, except mature erythrocytes, which have a very specialized function and minimal turnover of their constituents. Inside the lysosomal compartment, the degradation of endocytosed or autophagocytosed materials takes place in an acidic environment ( $\mathrm{pH} \sim 4-5$ ), which is maintained by ATP-dependent proton pumps present in the lysosomal membrane.

Following synthesis in the endoplasmic reticulum, lysosomal hydrolases are tagged with mannose-6-phosphate (MP) at the cis-Golgi area and then enclosed in transport vesicles (sometimes termed primary lysosomes, although they have a neutral $\mathrm{pH}$ ) in the trans-Golgi network (TGN) with the help of MP receptors. The vesicles, containing the newly produced hydrolases, are then transported to slightly acidic ( $\mathrm{pH}$ about 6) late endosomes, which arise from early endosomes containing endocytosed material. The lysosomal hydrolases are then activated when they release the MP receptors that are recirculated to the Golgi apparatus. Finally, the late endosomes mature to lysosomes that lack MP receptors, are rich in acid hydrolases, have a $\mathrm{pH}$ of 4-5, and contain material to be degraded (Terman et al., 2010).

The acidic lysosomal compartment contains a wide spectrum of hydrolytic enzymes, which play a major role in the intracellular recycling of proteins, polysaccharides, phospholipids and other biomolecules. Lysosomal proteases (cathepsins) are apparently the most important group of these enzymes. Lysosomal cathepsins can be categorized as cysteine (cathepsins B, C, F, H, K, L, O, S, V, W and X), aspartic (cathepsins D and E) and 
serine (cathepsin G) proteases (Eskelinen and Saftig, 2008, Kuester et al., 2008, Turk et al., 2002). They have a pH optimum of around 5, although several of them remain active even at neutral $\mathrm{pH}$ from minutes (cathepsin L) to hours (cathepsin S) (Droga-Mazovec et al., 2008).

Lysosomes may fuse with autophagosomes/endosomes to form 'hybrid' organelles containing material being degraded that originates both from the outside and inside of the cell. Following complete degradation of the enclosed material, lysosomes turn into 'resting' organelles, which under the electron microscope look homogeneous and moderately electron-dense. These resting lysosomes can then undergo new rounds of fusion (Luzio et al., 2007). The pronounced fusion and fission activity, characteristic of the lysosomal compartment (Luzio et al., 2007), allows lytic enzymes and other lysosomal contents to be distributed between different lysosomes (Fig. 1).

Because the lysosomal compartment is the center for normal autophagic turn-over of all organelles and most long-lived proteins, many of which are ferruginous compounds, lysosomes of all cells contain low mass redox-active iron (Fig. 2), explaining their vulnerability to oxidative stress (Kurz et al., 2008a, Kurz et al., 2008b). An additional way of loading lysosomes with iron is of importance when scavenger cells, such as macrophages, endocytose erythrocytes and thereby enrich their lysosomal compartment with redox-active iron. Because the lysosomal compartment is acidic and rich in reducing equivalents, such as cysteine and glutathione, any low mass iron would likely be Fe(II) (Schafer and Buettner, 2000, Terman et al., 2010). That in turn would promote the generation of hydroxyl radicals from hydrogen peroxide diffusing into this compartment. The hydroxyl radicals or, perhaps as importantly, ferryl and perferryl iron-centered radicals that form (Graf et al., 1984), may cause peroxidation of material under degradation, resulting in lipofuscin (see further below) or, if substantial, damage to and 
permeabilisation of the lysosomal membrane (Fig. 3). Lysosomal destabilization, with relocalization to the cytosol of potent hydrolytic enzymes and low mass iron, may induce either apoptosis or necrosis depending on the magnitude of lysosomal permeabilization.

Following receptor-mediated endocytosis, the plasma membrane-bound receptors are usually destroyed, while the ligands are released into the lysosomal compartment and degraded. One exception to this "rule of ligand-degradation" is the iron transport protein transferrin that is returned to the plasma membrane together with its receptor, while the iron, previously bound to transferrin, is released into late endosomes due to their acidic environment $(\mathrm{pH} \sim 6)$ and transported to the cytosol by transport proteins such as divalent metal transporter 1 (DMT1) (reviewed in Kurz et al., 2008b). There is evidence that iron may be transferred directly to mitochondria by direct contact with endosomes [the 'kiss and run' hypothesis (Richardson et al., 2010b)].

As pointed out above, lysosomes fuse with autophagosomes, or deliver part of their content, to form autophagolysosomes (Fig. 1). Here a variety of organelles and proteins are degraded into their building blocks, which in turn are reutilized by the anabolic machinery of the cell following their transport to the cytosol (reviewed in Klionsky, 2007, Terman et al., 2007). From a physiological point of view, the lysosomal compartment can be looked upon as a box, built of vacuoles that constantly fuse and divide, that receives enzymes from the TGN and substrates from either the outside or the inside of the cell. Following substrate degradation inside individual lysosomes, the products diffuse or are actively transported to the cytosol for reutilization.

Since many iron-containing macromolecules are degraded intralysosomally, low mass iron is released inside the lysosomal compartment. Because the lysosomes also contain reducing agents, for example glutathione, ascorbic acid and the amino acid cysteine, low mass iron likely exists as Fe(II) with the capacity to generate highly reactive 
radicals if exposed to hydrogen peroxide (reviewed in Kurz et al., 2008b). As a result, lysosomes are very sensitive to oxidative stress and their membranes easily peroxidized and permeabilized by the radicals that are formed secondary to Fenton-type reactions taking place in the lysosomes. The rupture of lysosomes with relocation of the lytic enzymes results in apoptosis or necrosis depending on the magnitude of this relocation (reviewed in Brunk et al., 2001). Consequently, keeping the concentration of redox-active iron in lyososomes as low as possible is important for the survival of cells exposed to oxidative stress. The rapid transport of low mass iron from lysosomes to the cytosol is thus important, as well as ways of temporarily binding iron in a non-redox-active form (Kurz et al., 2008b).

Autophagy is a non-stop biological renewal mechanism providing for lysosomal degradation of the cell's own constituents. It represents one of the main pathways for the turnover and reutilization of damaged or worn-out long-lived proteins and organelles. Interestingly, the multicatalytic proteinase complexes, proteasomes, which also play an important role in the turnover of macromolecules, are themselves degraded by autophagy (Cuervo et al., 1995). The implication of this is that impaired autophagy might result in defective proteasomes since they, together with mitochondria and other organelles, are then not properly renewed. The mechanisms involved in the formation of the autophagic double membrane (the phagophore), the inclusion of materials to be degraded, and the fusion of autophagosomes and lysosomes were recently elucidated as a result of the discovery in yeast of a large family of phylogenetically well preserved autophagy-related genes (ATG) (Klionsky, 2007, Shintani and Klionsky, 2004, Suzuki and Ohsumi, 2007, Yorimitsu and Klionsky, 2005).

To date, three different mechanisms of autophagy have been described in mammalian cells: macroautophagy (also known as just autophagy), microautophagy and 
chaperone mediated autophagy (CMA). Macroautophagy, which in at least a subset of cases is a non-selective process (Seglen et al., 1990), involves the sequestration within a double membrane-bounded vacuole of portions of the cytosol, including aggresomes, dysfunctional mitochondria or proteasomes, as well as long-lived soluble proteins. The early sequestration vacuole is devoid of lysosomal enzymes and termed an autophagosome. In consecutive steps, it fuses with lysosomes and with other vacuoles, eventually resulting in the formation of an autophagolysosome (also called autolysosome) within which the degradation of the cargo and the recycling of amino acids and other monomeric molecules, occurs (Cuervo, 2004, Kurz et al., 2008b, Yorimitsu and Klionsky, 2005).

Macroautophagy is the most universal type of autophagy, being involved in the degradation of practically any type of cellular material. Macroautophagy, and possibly other forms of autophagy, becomes activated under stress conditions, such as starvation, to generate essential building blocks by means of non-specific degradation of organelles and cytosolic macromolecules that are not critical to the survival of the cell (Terman and Brunk, 2005).

Subsequent to cellular damage, reparative autophagy follows, by which altered and malfunctioning structures are replaced. Such reparative autophagy is commonly seen, for example, following ionizing irradiation, virus infection, and hypoxic or oxidative stress (Bergamini, 2006, Kaushik and Cuervo, 2006, Persson et al., 2005). Interestingly, the postpartum period of starvation involves a period of enhanced autophagy in the liver, explaining why certain mutations that hinder autophagy are lethal (Yin et al., 2008). Recent evidence suggests that regular day-long periods of starvation may, by stimulating autophagy, help to "keep cells clean" and be beneficial and prolong life (Cuervo et al., 2005). 
The cell is not a stable entity but constantly remodeling; new molecules and organelles are continuously formed and degraded while the cell seemingly remains the same. Some molecules have half-lives of a few minutes while others may last for weeks. The turnover of cytosolic proteins and organelles is mainly dependent on the proteasomal and lysosomal pathways, which partly are able to substitute for each other (Fuertes et al., 2003, Pandey et al., 2007, Terman and Sandberg, 2002). Proteasomes mainly degrade short-lived, oxidized and malformed proteins (Chondrogianni and Gonos, 2010, Jung et al., 2009), while lysosomes are involved in autophagic degradation of long-lived proteins and all organelles (Kaushik et al., 2011, Yang and Klionsky, 2010).

Autophagy has recently been found to be a highly controlled process that is regulated by a large number of conserved autophagy related genes (ATGs) and is of fundamental importance for cellular survival (Klionsky, 2007, Shintani and Klionsky, 2004, Suzuki and Ohsumi, 2007, Yorimitsu and Klionsky, 2005). The autophagic degradation of iron-containing materials, such as ferritin and mitochondrial complexes, explains the presence of lysosomal redox-active iron. This makes these organelles uniquely sensitive to oxidative attack. Hydrogen peroxide is constantly produced in cells, mainly from mitochondria but also from cytosolic redox processes. Since some hydrogen peroxide escapes degradation by catalase and glutathione peroxidase and enters the lysosomal compartment, Fenton-type reactions and formation of hydroxyl radicals take place inside lysosomes (Walton and Lewis, 1916, Zdolsek et al., 1993, Zdolsek and Svensson, 1993) (Fig 3). As long as only small amounts of hydrogen peroxide enter lysosomes, the formation of hydroxyl radicals is limited and these probably react with material under degradation, which is the likely 
origin of lipofuscin that takes place in all cells but becomes obvious mainly in postmitotic cells that cannot dilute lipofuscin by cell division. However, in the presence of larger amounts of hydrogen peroxide, intralysosomal Fenton reactions may become more violent and result in lysosomal membrane permeabilization (LMP) with relocation of iron and lysosomal proteolytic enzymes to the cytosol with ensuing damage. The relocation of iron in redox-active form may cause further Fenton-type reactions with resulting oxidative damage to, for example, nuclear DNA (Kurz et al., 2004, Tenopoulou et al., 2005) and a variety of cytosolic structures. The release of, e.g., cathepsins B and D may activate apoptosis in a variety of ways, of which the best known is activation of Bid and Bax, with subsequent formation of pores in the outer mitochondrial membrane, release of cytochrome $c$ and other apoptogens that initiate the apoptotic cascade (Bidere et al., 2003, Brunk et al., 2001, Castino et al., 2007, Cirman et al., 2004, Guicciardi et al., 2004).

The lysosomal compartment consists of a large number of vacuoles. Those that have recently been engaged in degrading iron-rich compounds would be rich in potentially redox-active iron, while resting lysosomes may contain no iron at all. As will be pointed out later, this will be reflected in varying lysosomal sensitivity to oxidative stress (Nilsson et al., 1997). Apart from being a normal and continuous process, enhanced autophagy is also a way of creating materials for essential metabolism by degrading some cytoplasmic structures in case of starvation. Moreover, autophagy can be a protective mechanism that allows rapid removal of damaged structures (reparative autophagy) that may have resulted from various stresses (Bergamini, 2006, Kaushik and Cuervo, 2006). If successful, cells return to a normal state, but if damage has been substantial apoptosis may follow (apoptosis type II or autophagy-mediated apoptosis). One of the reasons for this kind of 
apoptosis may be that extensive autophagy results in particularly iron-rich lysosomes secondary to degradation of a large number of mitochondria and other ironcontaining compounds. In such a cell, even normal production of hydrogen peroxide may be enough to cause $\mathrm{HO} \cdot$-formation intralysosomally to such a degree that substantial LMP will result and apoptosis follows. Consequently, apoptosis type II may be a result of unsuccessful attempts to repair cellular damage by autophagy rather than an apoptotic pathway in its own right.

The cytosol contains a range of iron-binding proteins, such as metallothioneins, Hsp70 and ferritin (Baird et al., 2006, Kurz and Brunk, 2009, Kurz et al., 2011). These can all be autophagocytosed and then are able to bind lysosomal redox-active iron for a limited period of time until they are degraded. If these stress- or phase II proteins are abundant and their autophagy is rapid, the result may be a depression of redoxactive lysosomal iron of such magnitude that even substantial oxidative stress does not result in LMP and consequent cell death. This may be the reason why cells rich in stress proteins, such as cells of several highly malignant tumors, are relatively resistant to X-irradiation and/or exposure to anti-cancer agents that act by inducing oxidative stress (Berndt et al., 2010, Persson et al., 2005).

Ferritin is the main iron-storage protein and by binding iron in a non-redoxactive form it is also an important antioxidant. When stored iron is needed for synthesis of iron-containing structures, it has to be released from ferritin. Recent research has shown that the major mechanism for this iron release involves lysosomal digestion (Bridges and Hoffman, 1986, Garner et al., 1998, Kidane et al., 2006, Konijn et al., 1999, Kurz et al., 2011, Kwok and Richardson, 2004, Persson et al., 2003, Radisky and Kaplan, 1998, Roberts and Bomford, 1988, Sakaida et al., 1990, Tenopoulou et al., 2005, Vaisman et al., 1997, Yu et al., 2003b, Zhang et al., 2010). Iron 
is then relocated to the cytoplasm, probably by the participation of DMT1. Apart from the autophagic pathway, some ferritin is also degraded by proteasomes and these two pathways may be able to partially compensate for each other (De Domenico et al., 2006, De Domenico et al., 2009, Zhang et al., 2010). A less well documented, but still possible mechanism of iron release from ferritin is by way of pores in the ferritin molecules (Liu et al., 2003, Takagi et al., 1998).

Following autophagy, and prior to their degradation, apo-ferritin or ferritin containing a low amount of iron, i.e. ferritins with remaining iron-binding capacity, are able to bind intralysosomal iron and thereby temporarily protect the lysosomal membrane against iron-mediated oxidation (Garner et al., 1997, Garner et al., 1998, Kurz et al., 2011). On the contrary, if ferritin with a high degree of iron saturation, and no remaining iron binding capacity, is autophagocytosed and degraded, the lysosomal compartment is rather enriched with iron. Then lysosomes and cells become sensitized to oxidative stress (Kurz et al., 2011). This may be the reason why hepatocytes suddenly start to die in late stages of iron-overload when probably most cytosolic ferritin is iron-saturated. Overall, the regulation of lysosomal redox-active iron is probably of greatest importance when it comes to control of cellular sensitivity to oxidative stress.

\section{LYSOSOMAL ACCUMULATION OF LIPOFUSCIN AND ITS INFLUENCE ON AUTOPHAGY AND AGEING}

Lipofuscin (age pigment) is a non-degradable, yellowish-brown, autofluorescent, polymeric compound that slowly accumulates within aging long-lived postmitotic cells, such as neurons, retinal pigment epithelial (RPE) cells and myocardial cells, at a rate that is almost perfectly inversely correlated with species longevity (reviewed in 
Brunk and Terman, 2002). This interesting fact strongly suggests that lipofuscinaccumulation may be hazardous if extensive. If, for example, similar motor neurons from humans and mice are compared at the end of a normal lifespan, lipofuscin accumulation is about the same, although it occurs over about 90 or 2 years, respectively.

It should be noted that lipofuscin also accumulates in cultured cells undergoing replicative senescence (associated with a progressive decline in the cellular proliferation rate), or in cells whose proliferation is inhibited by pronounced densitydependent inhibition of growth. Studies on cultured cells have shown that increased ambient oxygen (40\%) dramatically increases lipofuscin formation, as does endocytosis of low mass iron and inhibition of lysosomal proteases (reviewed in Brunk and Terman, 2002). These findings suggest that lipofuscin forms secondary to iron-catalyzed peroxidation of material under degradation inside the lysosomal compartment.

Although rapid and effective, lysosomal (autophagic) degradation is not completely perfect. Even under normal conditions, some iron-catalyzed peroxidation occurs intralysosomally, resulting in oxidative modification of the autophagocytosed material, making it resistant to the hydrolytic activity of lysosomal enzymes. If cells do not divide, this material progressively accumulates within the lysosomal compartment in the form of lipofuscin inclusions. Basically, lipofuscin may be regarded as a non-degradable plastic-like polymer that slowly matures by intramolecular reorganization. Because lipofuscin is rich in iron, lipofuscin-loaded lysosomes may be sites of pronounced Fenton-type reactions, and especially sensitive to oxidative stress (Brun and Brunk, 1973, Brunk and Terman, 2002, Jolly et al., 1995). 
The major factors that influence lipofuscin formation seem to be the amount of lysosomal redox-active iron, lysosomal influx of hydrogen peroxide and the time allowed for oxidation of intralysosomal material under degradation. This suggests that intralysosomal ligation of iron in a non-redox-active state, low cellular production of hydrogen peroxide and rapid autophagic turnover are factors that would characterize long-lived species.

In professional scavengers, such as RPE cells and macrophages (foam cells) in atheroma, a large portion of lipofuscin (or ceroid) originates from endocytosed material (Lee et al., 1998, Nilsson et al., 2003). Depending on the nature of the autophagocytosed/endocytosed material, the composition of lipofuscin varies amongst different types of postmitotic cells, and no chemical formula can be given for this complex substance that is mainly composed of cross-linked protein and lipidaceous material (Brunk and Terman, 2002).

The accumulation of lipofuscin within the lysosomal compartment may compromise autophagic degradative capacity, prolonging the half-lives of long-lived proteins and organelles and thereby creating a situation in which cells are forced to exercise their functions with less than perfect tools. Consistent with this theory, the capacity for autophagic degradation is diminished in aged lipofuscin-loaded cells (Cuervo and Dice, 2000, Terman, 1995, Terman et al., 1999), which may lead to some serious consequences. For example, delayed degradation of mitochondria would result in increased damage by ROS because old and damaged mitochondria produce enhanced amounts of superoxide and hydrogen peroxide, additionally contributing to lipofuscinogenesis, and perhaps inducing apoptotic cell death (Fig 4).

The earlier described accumulation of iron in lipofuscin during the life span may finally result in such a high sensitivity of lysosomes of long-lived postmitotic cells to 
oxidation that even normal production of hydrogen peroxide may result in LMP, relocation of lysosomal enzymes and initiation of apoptotic cell death.

Recently, an elegant study on Caenorhabditis elegans added new evidence for the hypothesis that lipofuscin accumulation is causally related to aging and the deterioration of postmitotic cells. Since these tiny nematodes are transparent, lipofuscin can be measured directly by spectrofluorimetry in vivo. It was found that mutant nematodes, which live either longer or shorter than wild type animals, accumulate lipofuscin at a slower or quicker pace, respectively. It was also found that calorically restricted worms lived longer and accumulated lipofuscin more slowly than animals fed ad libitum. Finally, when wild-type siblings that aged differently - as evaluated by changes in their motility - were compared, it was found that the still mobile and youthful ones at day 11 of their life spans contained only $25 \%$ of the lipofuscin that was found in severely motility-impaired siblings of the same age. This implies that lipofuscin accumulation reflects biological rather than chronological age (Gerstbrein et al., 2005). The positive correlations between lipofuscin accumulation and hampered cellular function are in harmony with observations that chronic feeding of rats with green tea between the age of 12 and 19 months delays hippocampal accumulation of lipofuscin and improves learning and memory. Given that green tea is rich in polyphenolic compounds that happen to be good ironchelators, the findings suggest that reduction of redox-active lysosomal iron can be achieved pharmacologically (Assuncao et al., 2011).

The importance of autophagy for the removal of protein aggregates and delaying aging was further demonstrated in a recent study on Drosophila (Simonsen et al., 2007). During normal aging of the fly, the expression of the Atg8a gene (which is of importance for autophagy) decreases in neurons, resulting in the accumulation 
of aggregates of ubiquitinated protein. When the expression of Atg8a was upregulated, the aggregates disappeared and the flies showed an increased resistance to oxidative stress as well as a more than $50 \%$ prolonged lifespan.

\section{LYSOSOMAL IRON AND IONIZING IRRADIATION}

Apart from radiolytic cleavage of water leading to formation of hydroxyl radicals $\left(\mathrm{HO}^{\circ}\right)$, the simultaneous production of superoxide and hydrogen peroxide is a well-known effect of ionizing radiation to tissues (Halliwell and Gutteridge, 2007b, Persson et al., 2005). However, the possible influence of hydrogen peroxide on radiation-induced cellular damage does not usually seem to be fully taken into account. This is somewhat surprising since in 1962 Otto Warburg pointed out that the cellular effects of exposure to ionizing radiation or to hydrogen peroxide show substantial similarities (Warburg, 1962).

Subsequent studies on the damaging effects of randomly formed $\mathrm{HO}^{\bullet}$ indicated that these short-lived (half-life $\sim 10^{-9} \mathrm{sec}$ ) and extremely aggressive radicals react with nuclear DNA at the site of formation, causing adducts, mutations and single and double strand breaks. Even if it is not definitively proven that $\mathrm{HO}^{\circ}$-induced DNA damage is a major cause of cellular injury following irradiation, there is an overwhelming amount of indirect evidence (in part from the pronounced radiation sensitivity of cells from individuals with DNA repair defects) that this is indeed the case, and there seems to be little reason to question this dogma. However, apart from radiolytic cleavage of water, $\mathrm{HO}^{\bullet}$ can also be produced by Fenton-type (transition metal-mediated) reactions, which gives incentives to examine the occurrence of such reactions during ionizing irradiation.

Obviously, the presence of redox-active iron in direct contact with DNA would give rise to massive site-specific Fenton-type chemistry, given the radiation-induced production of hydrogen peroxide and superoxide. Under normal conditions, there are no indications of 
any significant amount of low mass redox-active iron that is in juxtaposition to DNA (Doulias et al., 2003, Kurz et al., 2004, Tenopoulou et al., 2005). However, as was recently demonstrated, under conditions of oxidative stress lysosomal rupture will occur, iron will be relocated, and DNA damage initiated (Doulias et al., 2003, Kurz et al., 2004, Persson et al., 2005, Tenopoulou et al., 2005).

Lysosomes show widely different sensitivity to oxidative stress (Nilsson et al., 1997). Using vital staining with lysosomotropic (acidotropic) fluorochromes, e.g. acridine orange or other available lysotrackers, it was found that after heavy oxidative stress some lysosomes always remain intact, while even low oxidative stress results in the rupture of a small but obviously very sensitive population of lysosomes (Nilsson et al., 1997). The explanation for this phenomenon is probably that some lysosomes are actively engaged in degradation of iron-containg macromolecules, while resting lysosomes may contain little or none of this transition metal (Terman et al., 2010).

Since the hydrogen peroxide that forms throughout the cell during irradiation is highly diffusible, it will enter the lysosomal compartment, meet redox-active iron and induce violent Fenton-type reactions with resultant LMP and release of lysosomal contents to the surrounding cytosol (Fig. 3). Dependent on the magnitude of lysosomal rupture, cell proliferation is stimulated or arrested by a minor or a somewhat more pronounced lysosomal destabilization, respectively, while apoptosis or necrosis have been found to follow moderate or major destabilization, respectively (Li et al., 2000, Terman et al., 2010). Consequently, the amelioration of LMP by chelating lysosomal redox-active iron in a non-redox-active form ought to reduce radiation sensitivity.

This hypothesis was earlier supported by findings following treatment with desferrioxamine (DFO) at high doses for several hours before irradiation (Persson et al., 2005). Unfortunately, this hydrophilic and high molecular weight drug has the 
disadvantage of being taken up only by endocytosis (Cable and Lloyd, 1999, Lloyd et al., 1991) and is retained in lysosomes where it causes iron-starvation and, ultimately, cell death (Kurz et al., 2008a, Kurz et al., 2008b). Therefore, DFO is not an ideal iron-chelator for cellular protection against oxidative stress. While salicyl isonicotinoyl hydrazone (SIH) has already been shown to give excellent protection from hydrogen peroxide-induced oxidative stress (Kurz et al., 2006, Kurz et al., 2008a), recent findings suggest that SIH also can be used to protect normal tissues from radiation damage and may allow exposure to a higher-than-normal-dose of ionizing radiation without causing damage in the normal tissue that is adjacent to a malignancy (Berndt et al., 2010).

So far few radiation-protective substances have been applied to patients undergoing irradiation for malignancies. An exception is amifostine (2-[(3-aminopropyl)amino]ethanethiol dihydrogen phosphate ester; WR-2721) that has been found to protect salivary glands during irradiation to cancers of the tongue and mouth. Amifostine is a thiol and a phosphate ester that following de-phosphorylation turns into a lysosomotropic iron chelator. Its radio-protective effect underlines the importance of lysosomal redox-active iron for LMP as an important contributor to the radiation effect (Yu et al., 2003a).

The additive effects of LMP, a consequence of intralysosomal Fenton-type reactions secondary to enhanced cellular amounts of hydrogen peroxide, on top of the effects induced by direct formation of hydroxyl radicals following radiolytic cleavage of water, are dependent on the presence of oxygen that allows formation of superoxide and hydrogen peroxide. The importance of this additive effect is illustrated by the well-known fact that hypoxic malignancies, e.g., those that infiltrate bones, respond less well to ionizing radiation. In hypoxic tissues there will be limited formation of superoxide and hydrogen peroxide and, consequently, little LMP will take place. If the lysosomal compartment of malignancies could be enriched in redox-active iron and that of normal cells depressed, 
ionizing irradiation might be made more effective on tumors and less damaging to normal tissues.

\section{MACROPHAGE LYSOSOMAL IRON AND ATHEROSCLEROSIS}

The initial phase of atherosclerosis is supposed to be related to endocytic uptake of minimally oxidized LDL by macrophages in the vessel intima. While it is unclear what factors cause LDL oxidation and why macrophages generally do not clear themselves from their lysosomal content of oxidized LDL but rather are converted to foam cells, many of which die by apoptosis and undergo calcification, it is obvious that further LDL oxidation takes place intralysosomally (Li et al., 1998a) and that macrophage lysosomal stability is affected (Li et al., 1998b).

Atherosclerosis has a tendency to start in arteries where the intima frequently may be damaged by turbulent blood flow, e.g., in areas of bifurcation. In such areas erythocytes are a common finding in the intima, where they may be engulfed by macrophages, which then temporarily will harbor hemoglobin under degradation and, consequently, some redox-active iron inside their lysosomal compartment (Nagy et al., 2010). It has been suggested that exocytosis of lysosomal contents from macrophages that have engulfed erythrocytes, in combination with superoxide produced during the respiratory burst that characterize macrophages during endocytosis, may result in intimal LDL oxidation followed by its uptake by the same or other macrophages (Yuan et al., 1996). If so, the first step in intimal LDL oxidation would be macrophage exocytosis of iron-rich lysosomal contents. This partial LDL oxidation would activate macrophage scavenger receptors and be followed by LDL endocytosis. Inside the macrophage lysosomal compartment, it is conceivable that the partly oxidized LDL will undergo further oxidation and form a partly polymerized 
material akin to lipofuscin. This would be particularly plausible if the lysosomal compartment is rich in redox-active iron and significantly exposed to hydrogen peroxide formed during the oxidative burst that macrophages produce during endocytosis.

\section{LYSOSOMAL IRON AND DIABETES}

For some reason, $\beta$-cells show poor capacity to degrade hydrogen peroxide and, thus, they are particularly sensitive to oxidative stress. This is quite pronounced for murine $\beta$-cells, which lack catalase, while human $\beta$-cells contain some of it (Lenzen et al., 1996). The high sensitivity of $\beta$-cells to the redox active compound alloxan might reflect this lack of defense against hydrogen peroxide produced during alloxan metabolism (Zhang and Brunk, 1993, Zhang et al., 1995). An additional reason for the high sensitivity of $\beta$-cells to oxidative stress is the fact that the insulin-containing granules are rich in iron, which also applies to their lysosomal compartment that by autophagy degrades granules that are not needed when blood sugar is low and little insulin released. Insulin is stored in crystalline form and stabilized by zinc that is close to iron in the periodic table. Consequently, zinc and iron are not easily discriminated and some iron ends up together with zinc in the insulin-storing granules, which may explain why in hemachromatosis and other iron-overload conditions, diabetes is a common complication (bronze-diabetes). It can be assumed that in $\beta$-cells an iron-enriched lysosomal compartment might undergo LMP and associated apoptosis even if only normal concentrations of cytosolic hydrogen peroxide are present (Olejnicka et al., 1999).

Diabetes type I is considered an autoimmune disease where the islands of Langerhans are invaded by immunocompetent cells with resultant loss of most or all 
$\beta$-cells (Augstein et al., 1998, Eisenbarth, 1986, Foulis et al., 1986, O'Brien et al., 1997). Since invading macrophages and neutrophils produce ROS, the extracellular environment of the $\beta$-cells in this autoimmune disease might be highly oxidative. Therefore, in this case as well, it is possible that the death of the insulin-producing cells is at least partly a result of their high sensitivity to oxidative stress.

\section{LYSOSOMAL IRON AND NEURODEGENERATIVE DISEASES}

Recently, substantial evidence for the involvement of oxidative stress and poorly ligated iron in a number of neurodegenerative diseases has come from several independent laboratories (reviewed in Kell, 2009, Kell, 2010).

In Huntington's disease, characterized by extensive degeneration of neurons within the corpus striatum, inclusion bodies, which contain large amounts of oxidized proteins, predominantly the Huntingtin protein, may act as oxidation centers and in combination with a disturbed iron-metabolism induce toxic levels of hydroxyl radicals (Henshall et al., 2009). Since the iron-chelator DFO, which is taken up by endocytosis, is protective in a mouse model, it is conceivable that enhanced levels of lysosomal redox-active iron are involved. The same may be true for a number of other inclusion-body diseases.

Parkinson's disease, which results from the death of dopaminergic neurons in the substantia nigra, is associated with oxidative stress and the involvement of iron (reviewed in Kell, 2009, Kell, 2010). It is possible that autophagy of highly iron-loaded neuromelanin (Double et al., 2003) lies behind this disease.

Alzheimer's disease, characterized by loss of neurons within the cognitive parts of the brain, is associated with oxidative stress and disturbed iron metabolism (reviewed in Kell, 2009, Kell, 2010). The formation of $\beta$-amyloid aggregates is enhanced by several heavy metals, including iron, and $\beta$-amyloid is known to bind iron (reviewed in Kell, 2009, 
Kell, 2010). Therefore endocytosis and autophagy of this material may be part of the pathophysiology of this disease (Zheng et al., 2009, Zheng et al., 2006).

Finally, Friedreich's ataxia is caused by a mutation in the mitochondrial ironchaperone frataxin that is involved in the insertion of iron into mitochondrial iron-sulphur clusters. In the presence of dysfunctional frataxin, mitochondrial ferritin becomes overloaded with iron (Richardson et al., 2010a). Following autophagy of such mitochondria the lysosomal compartment seems to become particularly iron-rich and thereby increasingly sensitive to oxidative stress (Kurz et al., 2011).

\section{CONCLUSIONS AND PERSPECTIVES ON THE FUTURE}

Iron is an essential transition metal utilized in an extensive range of electron-transport mechanisms. Mitochondrial oxidative phosphorylation and many cytosolic oxidative processes depend on the capacity of iron to alternate between valences. The needed ironsulphur and heme complexes are mainly manufactured in the mitochondria, while cellular uptake of iron-transferrin and release of iron from its store in ferritin involves participation of the lysosomal compartment. It might well be, although this is not clarified, that low mass redox-active iron only occurs inside lysosomes, while elsewhere it is bound and transported in non-redox-active form.

Iron seems to be very rapidly exported from the lysosomal compartment and the transient pool of what has been named the pool of labile, chelatable, iron is also rapidly turned over. A high amount of redox-active lysosomal iron makes these organelles, and thereby also the cell, sensitive to oxidative stress, while an autophagic influx of ironbinding proteins, such as ferritin, metallothioneins and certain heat-shock proteins is able to reduce lysosomal redox-active iron by temporarily binding it. If the autophagic influx of such proteins is persistent and high, the proportion of lysosomal redox-active iron in 
relation to total iron may be substantially reduced and cellular sensitivity to oxidative stress diminished.

In the future perhaps administration of lysosomotropic iron-chelators may be taken advantage of to prevent or treat disorders in which altered concentrations of lysosomal redox-active iron may be amongst the contributing factors. In contrast, if lysosomal accumulation of redox-active iron in malignant cells could be increased, it might significantly enhance the efficiency of ionic irradiation or exposure to drugs that induce oxidative stress. 


\section{REFERENCES}

Aisen P, Leibman A, Zweier J. Stoichiometric and site characteristics of the binding of iron to human transferrin. J Biol Chem 1978;253:1930-7.

Anderson GJ, Vulpe CD. Mammalian iron transport. Cell Mol Life Sci 2009;66:3241-61.

Arosio P, Ingrassia R, Cavadini P. Ferritins: a family of molecules for iron storage, antioxidation and more. Biochim Biophys Acta 2009;1790:589-99.

Assuncao M, Santos-Marques MJ, Carvalho F, Lukoyanov NV, Andrade JP. Chronic green tea consumption prevents age-related changes in rat hippocampal formation. Neurobiol Aging 2011;32:707-17.

Augstein P, Stephens LA, Allison J, Elefanty AG, Ekberg M, Kay TW, Harrison LC. Betacell apoptosis in an accelerated model of autoimmune diabetes. Mol Med 1998;4:495-501.

Baird SK, Kurz T, Brunk UT. Metallothionein protects against oxidative stress-induced lysosomal destabilization. Biochem J 2006;394:275-83.

Balla G, Jacob HS, Balla J, Rosenberg M, Nath K, Apple F, Eaton JW, Vercellotti GM. Ferritin: a cytoprotective antioxidant strategem of endothelium. J Biol Chem 1992;267:18148-53.

Balla J, Jacob HS, Balla G, Nath K, Eaton JW, Vercellotti GM. Endothelial-cell heme uptake from heme proteins: induction of sensitization and desensitization to oxidant damage. Proc Natl Acad Sci U S A 1993;90:9285-9.

Bergamini E. Autophagy: a cell repair mechanism that retards ageing and ageassociated diseases and can be intensified pharmacologically. Mol Aspects Med 2006;27:403-10.

Berndt C, Kurz T, Selenius M, Fernandes AP, Edgren MR, Brunk UT. Chelation of lysosomal iron protects against ionizing radiation. Biochem J 2010;432:295301.

Bidere N, Lorenzo HK, Carmona S, Laforge M, Harper F, Dumont C, Senik A. Cathepsin D triggers Bax activation, resulting in selective apoptosis-inducing factor (AIF) relocation in $\mathrm{T}$ lymphocytes entering the early commitment phase to apoptosis. J Biol Chem 2003;278:31401-11.

Bridges KR, Hoffman KE. The effects of ascorbic acid on the intracellular metabolism of iron and ferritin. J Biol Chem 1986;261:14273-7.

Brun A, Brunk U. Heavy metal localization and age related accumulation in the rat nervous system. A histochemical and atomic absorption spectrophotometric study. Histochemie 1973;34:333-42.

Brunk UT, Jones CB, Sohal RS. A novel hypothesis of lipofuscinogenesis and cellular aging based on interactions between oxidative stress and autophagocytosis. Mutat Res 1992;275:395-403.

Brunk UT, Neuzil J, Eaton JW. Lysosomal involvement in apoptosis. Redox Rep 2001;6:91-7.

Brunk UT, Terman A. Lipofuscin: Mechanisms of age-related accumulation and influence on cell functions. Free Radic Biol Med 2002;33:611-9.

Cable H, Lloyd JB. Cellular uptake and release of two contrasting iron chelators. J Pharm Pharmacol 1999;51:131-4.

Campanella A, Rovelli E, Santambrogio P, Cozzi A, Taroni F, Levi S. Mitochondrial ferritin limits oxidative damage regulating mitochondrial iron availability: hypothesis for a protective role in Friedreich ataxia. Hum Mol Genet 2009;18:1-11. 
Castino R, Bellio N, Nicotra G, Follo C, Trincheri NF, Isidoro C. Cathepsin D-Bax death pathway in oxidative stressed neuroblastoma cells. Free Radic Biol Med 2007;42:1305-16.

Chasteen ND, Harrison PM. Mineralization in ferritin: an efficient means of iron storage. J Struct Biol 1999;126:182-94.

Chondrogianni N, Gonos ES. Proteasome function determines cellular homeostasis and the rate of aging. Adv Exp Med Biol 2010;694:38-46.

Cirman T, Oresic K, Mazovec GD, Turk V, Reed JC, Myers RM, Salvesen GS, Turk B. Selective disruption of lysosomes in HeLa cells triggers apoptosis mediated by cleavage of Bid by multiple papain-like lysosomal cathepsins. J Biol Chem 2004;279:3578-87.

Cuervo AM. Autophagy: many paths to the same end. Mol Cell Biochem 2004;263:5572.

Cuervo AM, Bergamini E, Brunk UT, Droge W, Ffrench M, Terman A. Autophagy and aging: the importance of maintaining "clean" cells. Autophagy 2005;1:131-40.

Cuervo AM, Dice JF. Age-related decline in chaperone-mediated autophagy. J Biol Chem 2000;275:31505-13.

Cuervo AM, Palmer A, Rivett AJ, Knecht E. Degradation of proteasomes by lysosomes in rat liver. Eur J Biochem 1995;227:792-800.

De Domenico I, Vaughn MB, Li L, Bagley D, Musci G, Ward DM, Kaplan J. Ferroportinmediated mobilization of ferritin iron precedes ferritin degradation by the proteasome. EMBO J 2006;25:5396-404.

De Domenico I, Ward DM, Kaplan J. Specific iron chelators determine the route of ferritin degradation. Blood 2009;114:4546-51.

Donovan A, Lima CA, Pinkus JL, Pinkus GS, Zon LI, Robine S, Andrews NC. The iron exporter ferroportin/Slc40a1 is essential for iron homeostasis. Cell Metab 2005;1:191-200.

Double KL, Dedov VN, Fedorow H, Kettle E, Halliday GM, Garner B, Brunk UT. The comparative biology of neuromelanin and lipofuscin in the human brain. Cell Mol Life Sci 2008;65:1669-82.

Double KL, Gerlach M, Schunemann V, Trautwein AX, Zecca L, Gallorini M, Youdim MB, Riederer P, Ben-Shachar D. Iron-binding characteristics of neuromelanin of the human substantia nigra. Biochem Pharmacol 2003;66:489-94.

Doulias PT, Christoforidis S, Brunk UT, Galaris D. Endosomal and lysosomal effects of desferrioxamine: protection of HeLa cells from hydrogen peroxide-induced DNA damage and induction of cell-cycle arrest. Free Radic Biol Med 2003;35:719-28.

Droga-Mazovec G, Bojic L, Petelin A, Ivanova S, Romih R, Repnik U, Salvesen GS, Stoka V, Turk V, Turk B. Cysteine cathepsins trigger caspase-dependent cell death through cleavage of bid and antiapoptotic Bcl-2 homologues. J Biol Chem 2008;283:19140-50.

Dunn LL, Rahmanto YS, Richardson DR. Iron uptake and metabolism in the new millennium. Trends Cell Biol 2007;17:93-100.

Eisenbarth GS. Type I diabetes mellitus. A chronic autoimmune disease. N Engl J Med 1986;314:1360-8.

Eskelinen EL, Saftig P. Autophagy: A lysosomal degradation pathway with a central role in health and disease. Biochim Biophys Acta 2008. 
Esposito BP, Breuer W, Sirankapracha P, Pootrakul P, Hershko C, Cabantchik ZI. Labile plasma iron in iron overload: redox activity and susceptibility to chelation. Blood 2003;102:2670-7.

Foulis AK, Liddle CN, Farquharson MA, Richmond JA, Weir RS. The histopathology of the pancreas in type 1 (insulin-dependent) diabetes mellitus: a 25-year review of deaths in patients under 20 years of age in the United Kingdom. Diabetologia 1986;29:267-74.

Fuertes G, Villarroya A, Knecht E. Role of proteasomes in the degradation of shortlived proteins in human fibroblasts under various growth conditions. Int J Biochem Cell Biol 2003;35:651-64.

Gao X, Qian M, Campian JL, Marshall J, Zhou Z, Roberts AM, Kang YJ, Prabhu SD, Sun $\mathrm{XF}$, Eaton JW. Mitochondrial dysfunction may explain the cardiomyopathy of chronic iron overload. Free Radic Biol Med 2010;49:401-7.

Garner B, Li W, Roberg K, Brunk UT. On the cytoprotective role of ferritin in macrophages and its ability to enhance lysosomal stability. Free Radic Res 1997;27:487-500.

Garner B, Roberg K, Brunk UT. Endogenous ferritin protects cells with iron-laden lysosomes against oxidative stress. Free Radic Res 1998;29:103-14.

Gerstbrein B, Stamatas G, Kollias N, Driscoll M. In vivo spectrofluorimetry reveals endogenous biomarkers that report healthspan and dietary restriction in Caenorhabditis elegans. Aging Cell 2005;4:127-37.

Graf E, Mahoney JR, Bryant RG, Eaton JW. Iron-catalyzed hydroxyl radical formation. Stringent requirement for free iron coordination site. J Biol Chem 1984;259:3620-4.

Graham RM, Reutens GM, Herbison CE, Delima RD, Chua AC, Olynyk JK, Trinder D. Transferrin receptor 2 mediates uptake of transferrin-bound and nontransferrin-bound iron. J Hepatol 2008;48:327-34.

Guicciardi ME, Leist M, Gores GJ. Lysosomes in cell death. Oncogene 2004;23:288190.

Gunshin H, Mackenzie B, Berger UV, Gunshin Y, Romero MF, Boron WF, Nussberger S, Gollan JL, Hediger MA. Cloning and characterization of a mammalian protoncoupled metal-ion transporter. Nature 1997;388:482-8.

Halliwell B, Gutteridge JMC. Antioxidant defences: endogenous and diet derived. Free Radicals in Biology and Medicine. 4th ed. Oxford: Oxford University Press; 2007a. p. 79-186.

Halliwell B, Gutteridge JMC. The chemistry of free radicals and related 'reactive species'. Free Radicals in Biology and Medicine. 4th ed. Oxford: Oxford University Press; 2007b. p. 30-78.

Harrison PM, Arosio P. The ferritins: molecular properties, iron storage function and cellular regulation. Biochim Biophys Acta 1996;1275:161-203.

Hatcher HC, Singh RN, Torti FM, Torti SV. Synthetic and natural iron chelators: therapeutic potential and clinical use. Future Med Chem 2009;1:1643-70.

Henshall TL, Tucker B, Lumsden AL, Nornes S, Lardelli MT, Richards RI. Selective neuronal requirement for huntingtin in the developing zebrafish. Hum Mol Genet 2009;18:4830-42.

Hentze MW, Kuhn LC. Molecular control of vertebrate iron metabolism: mRNA-based regulatory circuits operated by iron, nitric oxide, and oxidative stress. Proc Natl Acad Sci U S A 1996;93:8175-82. 
Hentze MW, Muckenthaler MU, Galy B, Camaschella C. Two to tango: regulation of Mammalian iron metabolism. Cell 2010;142:24-38.

Jolly RD, Douglas BV, Davey PM, Roiri JE. Lipofuscin in bovine muscle and brain: a model for studying age pigment. Gerontology 1995;41:283-95.

Jung T, Catalgol B, Grune T. The proteasomal system. Mol Aspects Med 2009;30:191296.

Kaushik S, Bandyopadhyay U, Sridhar S, Kiffin R, Martinez-Vicente M, Kon M, Orenstein SJ, Wong E, Cuervo AM. Chaperone-mediated autophagy at a glance. J Cell Sci 2011;124:495-9.

Kaushik S, Cuervo AM. Autophagy as a cell-repair mechanism: activation of chaperone-mediated autophagy during oxidative stress. Mol Aspects Med 2006;27:444-54.

Kawabata H, Germain RS, Ikezoe T, Tong X, Green EM, Gombart AF, Koeffler HP. Regulation of expression of murine transferrin receptor 2. Blood 2001;98:1949-54.

Kell DB. Iron behaving badly: inappropriate iron chelation as a major contributor to the aetiology of vascular and other progressive inflammatory and degenerative diseases. BMC Med Genomics 2009;2:2.

Kell DB. Towards a unifying, systems biology understanding of large-scale cellular death and destruction caused by poorly liganded iron: Parkinson's, Huntington's, Alzheimer's, prions, bactericides, chemical toxicology and others as examples. Arch Toxicol 2010;84:825-89.

Kidane TZ, Sauble E, Linder MC. Release of iron from ferritin requires lysosomal activity. Am. J. Physiol. Cell Physiol. 2006;291:C445-55.

Klionsky DJ. Autophagy: from phenomenology to molecular understanding in less than a decade. Nat Rev Mol Cell Biol 2007;8:931-7.

Knutson MD, Oukka M, Koss LM, Aydemir F, Wessling-Resnick M. Iron release from macrophages after erythrophagocytosis is up-regulated by ferroportin 1 overexpression and down-regulated by hepcidin. Proc Natl Acad Sci U S A 2005;102:1324-8.

Konijn AM, Glickstein H, Vaisman B, Meyron-Holtz EG, Slotki IN, Cabantchik ZI. The cellular labile iron pool and intracellular ferritin in K562 cells. Blood 1999;94:2128-34.

Kuester D, Lippert H, Roessner A, Krueger S. The cathepsin family and their role in colorectal cancer. Pathol Res Pract 2008;204:491-500.

Kurz T, Brunk UT. Autophagy of HSP70 and chelation of lysosomal iron in a nonredox-active form. Autophagy 2009;5:93-5.

Kurz T, Eaton J, Brunk U. Redox activity within the lysosomal compartment: Implications for aging and apoptosis. Antioxid Redox Signal 2010;13:511-23.

Kurz T, Gustafsson B, Brunk UT. Intralysosomal iron chelation protects against oxidative stress-induced cellular damage. FEBS J 2006;273:3106-17.

Kurz T, Gustafsson B, Brunk UT. Cell sensitivity to oxidative stress is influenced by ferritin autophagy. Free Radic Biol Med 2011;50:1647-58.

Kurz T, Leake A, Von Zglinicki T, Brunk UT. Relocalized redox-active lysosomal iron is an important mediator of oxidative-stress-induced DNA damage. Biochem J 2004;378:1039-45.

Kurz T, Terman A, Gustafsson B, Brunk UT. Lysosomes and oxidative stress in aging and apoptosis. Biochim Biophys Acta 2008a;1780:1291-303. 
Kurz T, Terman A, Gustafsson B, Brunk UT. Lysosomes in iron metabolism, ageing and apoptosis. Histochem Cell Biol 2008b;129:389-406.

Kwok JC, Richardson DR. Examination of the mechanism(s) involved in doxorubicinmediated iron accumulation in ferritin: studies using metabolic inhibitors, protein synthesis inhibitors, and lysosomotropic agents. Mol Pharmacol 2004;65:181-95.

Lee FY, Lee TS, Pan CC, Huang AL, Chau LY. Colocalization of iron and ceroid in human atherosclerotic lesions. Atherosclerosis 1998;138:281-8.

Lenzen S, Drinkgern J, Tiedge M. Low antioxidant enzyme gene expression in pancreatic islets compared with various other mouse tissues. Free Radic Biol Med 1996;20:463-6.

Levi S, Corsi B, Bosisio M, Invernizzi R, Volz A, Sanford D, Arosio P, Drysdale J. A human mitochondrial ferritin encoded by an intronless gene. J Biol Chem 2001;276:24437-40.

Li W, Yuan X, Nordgren G, Dalen H, Dubowchik GM, Firestone RA, Brunk UT. Induction of cell death by the lysosomotropic detergent MSDH. FEBS Lett 2000;470:35-9.

Li W, Yuan XM, Brunk UT. OxLDL-induced macrophage cytotoxicity is mediated by lysosomal rupture and modified by intralysosomal redox-active iron. Free Radic Res 1998a;29:389-98.

Li W, Yuan XM, Olsson AG, Brunk UT. Uptake of oxidized LDL by macrophages results in partial lysosomal enzyme inactivation and relocation. Arterioscler Thromb Vasc Biol 1998b;18:177-84.

Liu X, Jin W, Theil EC. Opening protein pores with chaotropes enhances Fe reduction and chelation of Fe from the ferritin biomineral. Proc Natl Acad Sci U S A 2003;100:3653-8.

Lloyd JB, Cable H, Rice-Evans C. Evidence that desferrioxamine cannot enter cells by passive diffusion. Biochem Pharmacol 1991;41:1361-3.

Lopes GK, Schulman HM, Hermes-Lima M. Polyphenol tannic acid inhibits hydroxyl radical formation from Fenton reaction by complexing ferrous ions. Biochim Biophys Acta 1999;1472:142-52.

Loreal O, Gosriwatana I, Guyader D, Porter J, Brissot P, Hider RC. Determination of non-transferrin-bound iron in genetic hemochromatosis using a new HPLCbased method. J Hepatol 2000;32:727-33.

Luzio JP, Pryor PR, Bright NA. Lysosomes: fusion and function. Nat Rev Mol Cell Biol 2007;8:622-32.

Mandel S, Weinreb O, Reznichenko L, Kalfon L, Amit T. Green tea catechins as brainpermeable, non toxic iron chelators to "iron out iron" from the brain. J Neural Transm Suppl 2006:249-57.

McCance RA, Widdowson EM. The absorption and excretion of iron following oral and intravenous administration. J Physiol 1938;94:148-54.

Mims MP, Prchal JT. Divalent metal transporter 1. Hematology 2005;10:339-45.

Morgan EH. Transferrin, biochemistry, physiology and clinical significance. Mol Aspects Med 1981;4:1-123.

Muhlenhoff U, Lill R. Biogenesis of iron-sulfur proteins in eukaryotes: a novel task of mitochondria that is inherited from bacteria. Biochim Biophys Acta 2000;1459:370-82.

Munoz M, Villar I, Garcia-Erce JA. An update on iron physiology. World J Gastroenterol 2009;15:4617-26. 
Nagy E, Eaton JW, Jeney V, Soares MP, Varga Z, Galajda Z, Szentmiklosi J, Mehes G, Csonka T, Smith A, Vercellotti GM, Balla G, Balla J. Red cells, hemoglobin, heme, iron, and atherogenesis. Arterioscler Thromb Vasc Biol 2010;30:1347-53.

Nemeth E, Preza GC, Jung CL, Kaplan J, Waring AJ, Ganz T. The N-terminus of hepcidin is essential for its interaction with ferroportin: structure-function study. Blood 2006;107:328-33.

Nilsson E, Ghassemifar R, Brunk UT. Lysosomal heterogeneity between and within cells with respect to resistance against oxidative stress. Histochem J 1997;29:857-65.

Nilsson SE, Sundelin SP, Wihlmark U, Brunk UT. Aging of cultured retinal pigment epithelial cells: oxidative reactions, lipofuscin formation and blue light damage. Doc Ophthalmol 2003;106:13-6.

O'Brien BA, Harmon BV, Cameron DP, Allan DJ. Apoptosis is the mode of beta-cell death responsible for the development of IDDM in the nonobese diabetic (NOD) mouse. Diabetes 1997;46:750-7.

Olejnicka BT, Andersson A, Tyrberg B, Dalen H, Brunk UT. Beta-cells, oxidative stress, lysosomal stability, and apoptotic/necrotic cell death. Antioxid Redox Signal 1999;1:305-15.

Pandey UB, Nie Z, Batlevi Y, McCray BA, Ritson GP, Nedelsky NB, Schwartz SL, DiProspero NA, Knight MA, Schuldiner O, Padmanabhan R, Hild M, Berry DL, Garza D, Hubbert CC, Yao TP, Baehrecke EH, Taylor JP. HDAC6 rescues neurodegeneration and provides an essential link between autophagy and the UPS. Nature 2007;447:859-63.

Paradkar PN, Zumbrennen KB, Paw BH, Ward DM, Kaplan J. Regulation of mitochondrial iron import through differential turnover of mitoferrin 1 and mitoferrin 2. Mol Cell Biol 2009;29:1007-16.

Persson HL, Kurz T, Eaton JW, Brunk UT. Radiation-induced cell death: importance of lysosomal destabilization. Biochem J 2005;389:877-84.

Persson HL, Yu Z, Tirosh O, Eaton JW, Brunk UT. Prevention of oxidant-induced cell death by lysosomotropic iron chelators. Free Radic Biol Med 2003;34:1295305.

Ponka P. Tissue-specific regulation of iron metabolism and heme synthesis: distinct control mechanisms in erythroid cells. Blood 1997;89:1-25.

Ponka P, Beaumont C, Richardson DR. Function and regulation of transferrin and ferritin. Semin Hematol 1998;35:35-54.

Radisky DC, Kaplan J. Iron in cytosolic ferritin can be recycled through lysosomal degradation in human fibroblasts. Biochem J 1998;336:201-5.

Richardson DR, Huang ML, Whitnall M, Becker EM, Ponka P, Rahmanto YS. The ins and outs of mitochondrial iron-loading: the metabolic defect in Friedreich's ataxia. J Mol Med 2010a;88:323-9.

Richardson DR, Lane DJ, Becker EM, Huang ML, Whitnall M, Rahmanto YS, Sheftel AD, Ponka P. Mitochondrial iron trafficking and the integration of iron metabolism between the mitochondrion and cytosol. Proc Natl Acad Sci U S A 2010b;107:10775-82.

Richardson DR, Ponka P. The molecular mechanisms of the metabolism and transport of iron in normal and neoplastic cells. Biochim Biophys Acta 1997;1331:1-40.

Roberts S, Bomford A. Ferritin iron kinetics and protein turnover in K562 cells. J Biol Chem 1988;263:19181-7. 
Rouault T, Klausner R. Regulation of iron metabolism in eukaryotes. Curr Top Cell Regul 1997;35:1-19.

Rouault TA. The role of iron regulatory proteins in mammalian iron homeostasis and disease. Nat Chem Biol 2006;2:406-14.

Sakaida I, Kyle ME, Farber JL. Autophagic degradation of protein generates a pool of ferric iron required for the killing of cultured hepatocytes by an oxidative stress. Mol Pharmacol 1990;37:435-42.

Santambrogio P, Biasiotto G, Sanvito F, Olivieri S, Arosio P, Levi S. Mitochondrial ferritin expression in adult mouse tissues. J Histochem Cytochem 2007;55:1129-37.

Schafer FQ, Buettner GR. Acidic $\mathrm{pH}$ amplifies iron-mediated lipid peroxidation in cells. Free Radic Biol Med 2000;28:1175-81.

Seglen PO, Gordon PB, Holen I. Non-selective autophagy. Semin Cell Biol 1990;1:4418.

Sharp P, Srai SK. Molecular mechanisms involved in intestinal iron absorption. World J Gastroenterol 2007;13:4716-24.

Shaw GC, Cope JJ, Li L, Corson K, Hersey C, Ackermann GE, Gwynn B, Lambert AJ, Wingert RA, Traver D, Trede NS, Barut BA, Zhou Y, Minet E, Donovan A, Brownlie A, Balzan R, Weiss MJ, Peters LL, Kaplan J, Zon LI, Paw BH. Mitoferrin is essential for erythroid iron assimilation. Nature 2006;440:96-100.

Sheftel AD, Zhang AS, Brown C, Shirihai OS, Ponka P. Direct interorganellar transfer of iron from endosome to mitochondrion. Blood 2007;110:125-32.

Shintani T, Klionsky DJ. Autophagy in health and disease: a double-edged sword. Science 2004;306:990-5.

Simonsen A, Cumming RC, Brech A, Isakson P, Schubert DR, Finley KD. Promoting basal levels of autophagy in the nervous system enhances longevity and oxidant resistance in adult Drosophila. Autophagy 2007;4:in press.

Suzuki K, Ohsumi Y. Molecular machinery of autophagosome formation in yeast, Saccharomyces cerevisiae. FEBS Lett 2007;581:2156-61.

Takagi H, Shi D, Ha Y, Allewell NM, Theil EC. Localized unfolding at the junction of three ferritin subunits. A mechanism for iron release? J Biol Chem 1998;273:18685-8.

Tenopoulou M, Doulias PT, Barbouti A, Brunk U, Galaris D. Role of compartmentalized redox-active iron in hydrogen peroxide-induced DNA damage and apoptosis. Biochem J 2005;387:703-10.

Terman A. The effect of age on formation and elimination of autophagic vacuoles in mouse hepatocytes. Gerontology 1995;41:319-26.

Terman A, Brunk UT. Autophagy in cardiac myocyte homeostasis, aging, and pathology. Cardiovasc Res 2005;68:355-65.

Terman A, Dalen H, Brunk UT. Ceroid/lipofuscin-loaded human fibroblasts show decreased survival time and diminished autophagocytosis during amino acid starvation. Exp Gerontol 1999;34:943-57.

Terman A, Gustafsson B, Brunk UT. Autophagy, organelles and ageing. J Pathol 2007;211:134-43.

Terman A, Kurz T, Navratil M, Arriaga E, Brunk U. Mitochondrial turnover and aging of long-lived postmitotic cells: The mitochondrial-lysosomal axis theory of aging. Antioxid Redox Signal 2010;12:503-35.

Terman A, Sandberg S. Proteasome inhibition enhances lipofuscin formation. Ann N Y Acad Sci 2002;973:309-12. 
Troadec MB, Ward DM, Lo E, Kaplan J, De Domenico I. Induction of FPN1 transcription by MTF-1 reveals a role for ferroportin in transition metal efflux. Blood 2010;116:4657-64.

Turk V, Turk B, Guncar G, Turk D, Kos J. Lysosomal cathepsins: structure, role in antigen processing and presentation, and cancer. Adv Enzyme Regul 2002;42:285-303.

Vaisman B, Fibach E, Konijn AM. Utilization of intracellular ferritin iron for hemoglobin synthesis in developing human erythroid precursors. Blood 1997;90:831-8.

Walton JH, Lewis HA. The partition coefficients of hydrogen peroxide between water and certain organic solvents. J Am Chem Soc 1916;38:633-8.

Warburg OH (1962). New Methods of Cell Physiology. Applied to Cancer, Photosynthesis, and Mechanism of X-Ray Action., (Editor ed.). New York: Interscience Publishers.

West AP, Jr., Bennett MJ, Sellers VM, Andrews NC, Enns CA, Bjorkman PJ. Comparison of the interactions of transferrin receptor and transferrin receptor 2 with transferrin and the hereditary hemochromatosis protein HFE. J Biol Chem 2000;275:38135-8.

Xu J, Marzetti E, Seo AY, Kim JS, Prolla TA, Leeuwenburgh C. The emerging role of iron dyshomeostasis in the mitochondrial decay of aging. Mech Ageing Dev 2010;131:487-93.

Yang Z, Klionsky DJ. Mammalian autophagy: core molecular machinery and signaling regulation. Curr Opin Cell Biol 2010;22:124-31.

Yin XM, Ding WX, Gao W. Autophagy in the liver. Hepatology 2008;47:1773-85.

Yorimitsu T, Klionsky DJ. Autophagy: molecular machinery for self-eating. Cell Death Differ 2005;12:1542-52.

Yu Z, Eaton JW, Persson HL. The radioprotective agent, amifostine, suppresses the reactivity of intralysosomal iron. Redox Rep 2003a;8:347-55.

Yu Z, Persson HL, Eaton JW, Brunk UT. Intralysosomal iron: a major determinant of oxidant-induced cell death. Free Radic Biol Med 2003b;34:1243-52.

Yuan XM, Anders WL, Olsson AG, Brunk UT. Iron in human atheroma and LDL oxidation by macrophages following erythrophagocytosis. Atherosclerosis 1996;124:61-73.

Zdolsek J, Zhang H, Roberg K, Brunk U. H202-mediated damage to lysosomal membranes of J-774 cells. Free Radic Res Commun 1993;18:71-85.

Zdolsek JM, Svensson I. Effect of reactive oxygen species on lysosomal membrane integrity. A study on a lysosomal fraction. Virchows Arch B Cell Pathol Incl Mol Pathol 1993;64:401-6.

Zhang H, Brunk UT. Alloxan cytotoxicity is highly potentiated by plasma membraneand lysosomal-associated iron--a study on a model system of cultured J-774 cells. Diabetologia 1993;36:707-15.

Zhang H, Ollinger K, Brunk U. Insulinoma cells in culture show pronounced sensitivity to alloxan-induced oxidative stress. Diabetologia 1995;38:635-41.

Zhang Y, Mikhael M, Xu D, Li Y, Soe-Lin S, Ning B, Li W, Nie G, Zhao Y, Ponka P. Lysosomal proteolysis is the primary degradation pathway for cytosolic ferritin and cytosolic ferritin degradation is necessary for iron exit. Antioxid Redox Signal 2010;13:999-1009. 
Zheng L, Kagedal K, Dehvari N, Benedikz E, Cowburn R, Marcusson J, Terman A. Oxidative stress induces macroautophagy of amyloid beta-protein and ensuing apoptosis. Free Radic Biol Med 2009;46:422-9.

Zheng L, Roberg K, Jerhammar F, Marcusson J, Terman A. Autophagy of amyloid betaprotein in differentiated neuroblastoma cells exposed to oxidative stress. Neurosci Lett 2006;394:184-9. 


\section{FIGURE LEGENDS:}

Fig. 1:

The lysosomal compartment. The cell takes up extracellular material by invagination of the plasma membrane (endocytosis), thereby forming early endosomes, which mature into acidified late endosomes. The latter receive lysosomal enzymes by fusion with secretory vesicles from the trans-Golgi network (TGN). Further maturation leads to lysosome formation. Cytosolic macromolecules may be directly engulfed by invaginations of the lysosomal membrane (microautophagy), whereas organelles (e.g., mitochondria) are being enclosed by a newly formed phagophore, resulting in the formation of an autophagosome (macroautophagy), which then fuses with either a late endosome or a lysosome (or, perhaps, with secretory vesicles from the TGN), forming an autophagolysosome. Certain proteins are delivered to lysosomes with the help of chaperones, such as Hsp73 (chaperone-mediated autophagy).

Fig. 2:

Demonstration of lysosomal iron in HeLa and J774 cells using the sensitive cytochemical sulfide silver method. Glutaraldehyde-fixed cultured cells were exposed to ammonium sulfide at $\mathrm{pH} 12$ and then developed in a colloid-protected (gum arabic) solution containing silver lactate and the reducing agent hydroquinone. Tiny silver particles precipitate and gradually enlarge to a size visible by light microscopy. The process is akin to physical development of a photographic plate. After a short development time of 25 min (A), only very iron-rich lysosomes are visible in Hela cells (arrows). These lysosomes most probably correspond to autophagolysosomes that are engaged in the degradation of iron-containing material, such as ferrritin or mitochondrial complexes. 
After 40 min of development (B), a strong general lysosomal pattern is seen, reflecting the fact that most HeLa cell lysosomes contain some low-mass iron.

Control $\mathrm{J} 774$ cells (C) and cells exposed to $10 \mathrm{mM} \mathrm{NH}_{4} \mathrm{Cl}$ for $10 \mathrm{~min}$ (D) show about the same degree of distinct granular, lysosomal-sized silver precipitates, while cells exposed to $10 \mathrm{mM} \mathrm{NH}_{4} \mathrm{Cl}$ for $4 \mathrm{~h}(\mathrm{E})$ contain few such precipitates (developing time: about $50 \mathrm{~min}$ ) showing that inhibited intralysosomal degradation results in lysosomes free of iron. The pronounced cytosolic vacuolization is a function of depressed autophagocytotic degradation creating enhanced osmotic pressure. Cells exposed to an iron-phosphate complex for $4 \mathrm{~h}$, and then returned to standard culture conditions for another $2 \mathrm{~h}(\mathrm{~F})$ show pronounced silver precipitation, indicating large amounts of lysosomal low molecular weight iron and that the method is able to demonstrate iron (developing time: about 20 $\min )$. Bar $=30 \mu \mathrm{m}$. Panels C-F reprinted from Yu et al., 2003b, with permission from Elsevier.

Fig. 3:

Results of intralysosomal formation of hydroxyl radicals. Hydrogen peroxide is formed normally, mainly from mitochondria. It is efficiently inactivated by the cell's antioxidative shield. Only a small portion of this oxidant manages to diffuse into lysosomes, a compartment rich in cysteine and redox-active iron, the latter originating from the degradation of a variety of iron-containing proteins. Hydrogen peroxide and ferrous iron react in the Fenton reaction, yielding hydroxyl radicals. This process gives rise to intralysosomal oxidation/peroxidation with resulting damage to the lysosomal membrane and macromolecules undergoing autophagic degradation. Some oxidation products polymerize and become undegradable (lipofuscin) and accumulate in lysosomes of longlived postmitotic cells, which do not dilute the pigment by division. 
Fig. 4:

Cellular accumulation of waste material is a consequence of imperfect autophagy. Lysosomal enzymes are produced in the trans-Golgi network (TGN) and by secretory vesicles transported to late endosomes that acidify and mature into lysosomes (see Fig. 1), which in turn fuse with autophagosomes. The continual fusion and fission of the lysosomal vacuoles ensures the distribution of acid hydrolases within the lysosomal compartment, including autophagosomes. In contrast to a young cell (A) that has only few lysosomes containing the undegradable age-pigment lipofuscin (Lf), senescent postmitotic cells (B) contain large numbers of Lf-containing lysosomes, to which more and more lysosomal enzymes are directed in a useless effort to degrade lipofuscin. These lysosomal enzymes are lost for useful purposes (e.g., for the degradation of newly autophagocytosed material), resulting in a delayed turnover and the accumulation of waste products. Damaged/dysfunctional mitochondria are indicated by dark shading. 


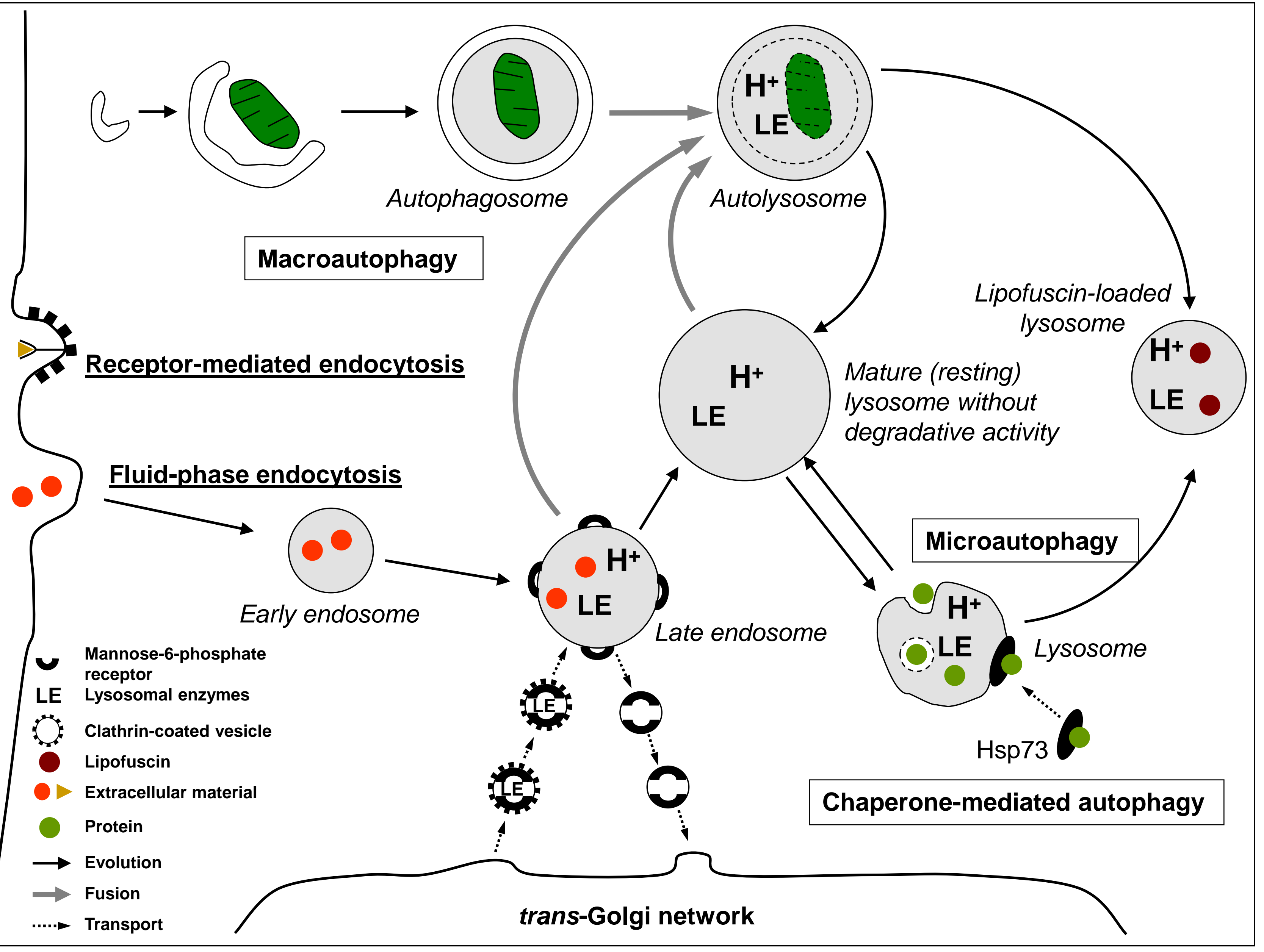


Click here to download high resolution image
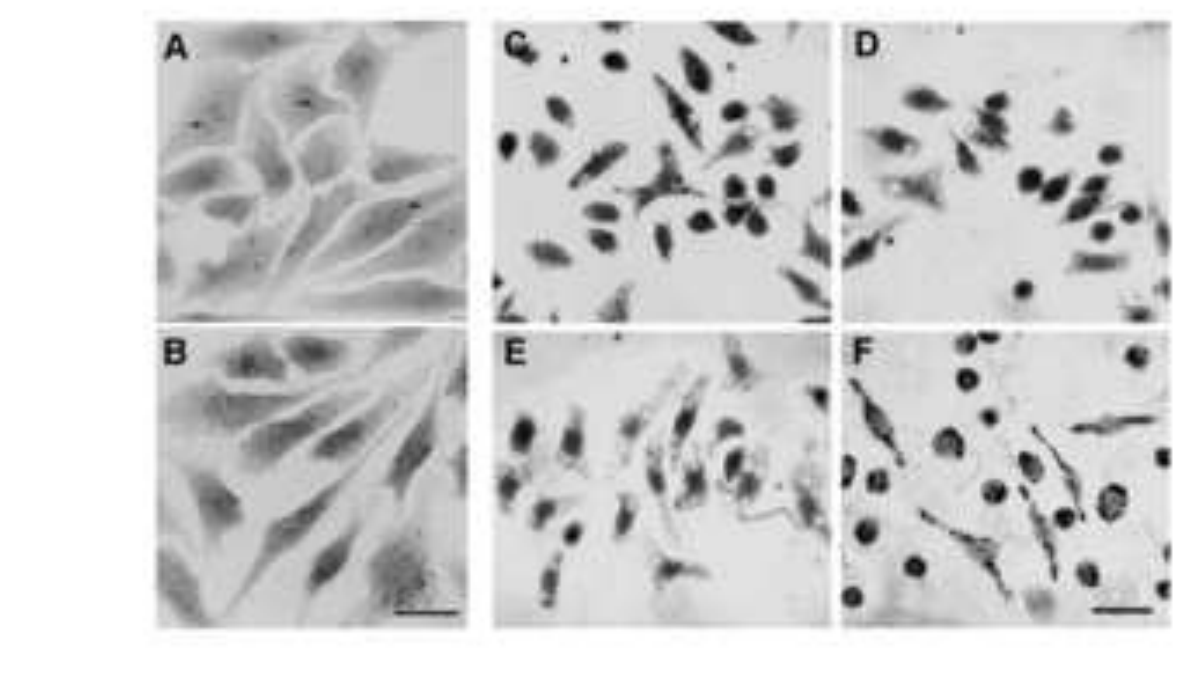

Fig. 2

Fig. 2

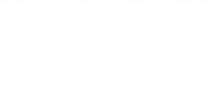

(
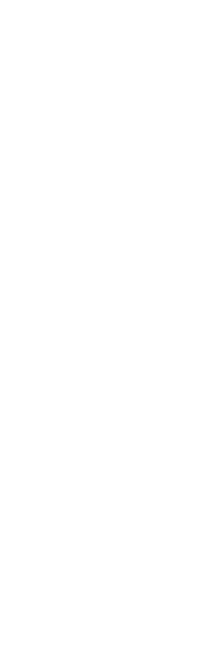


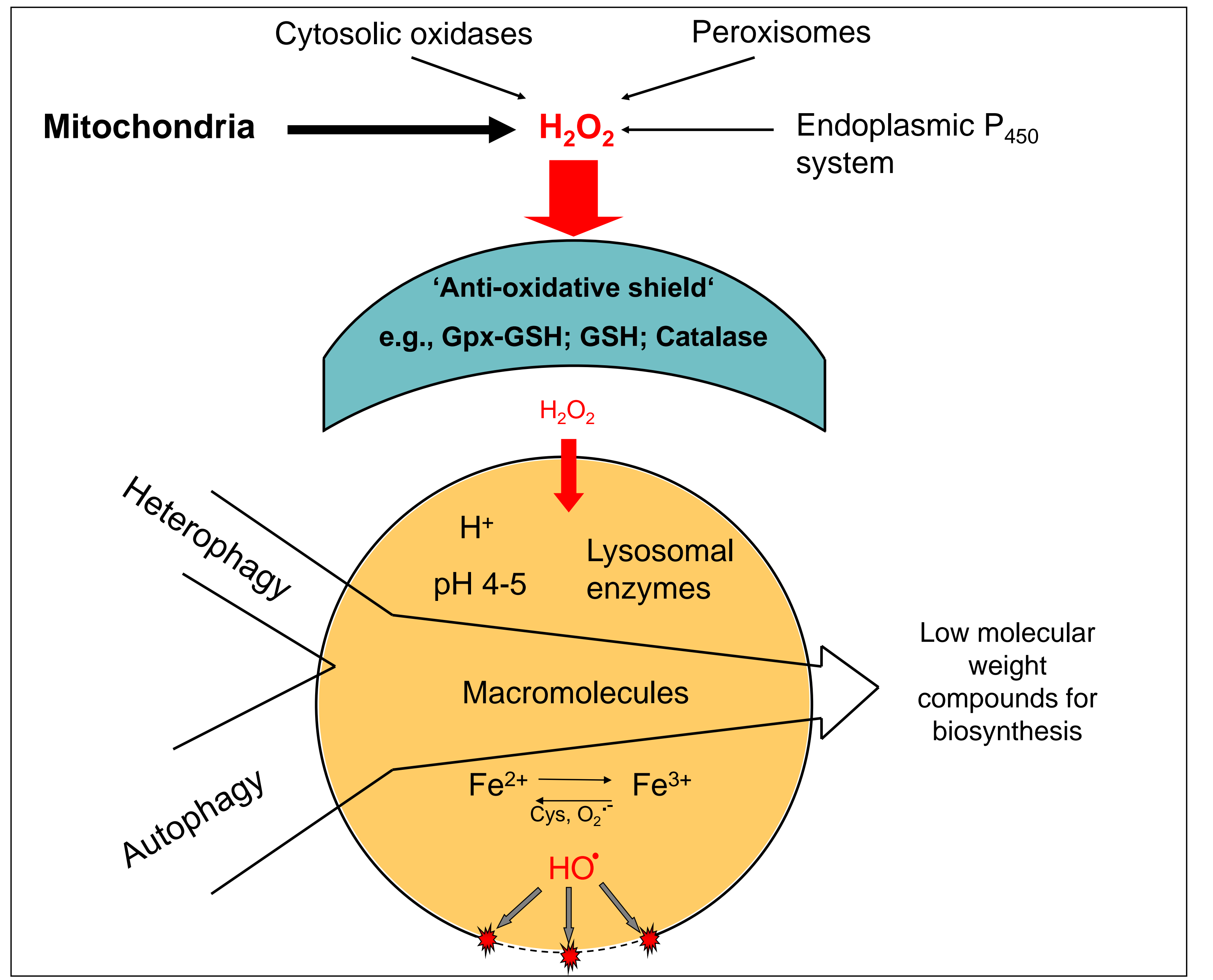




\section{(B) Senescent cell}
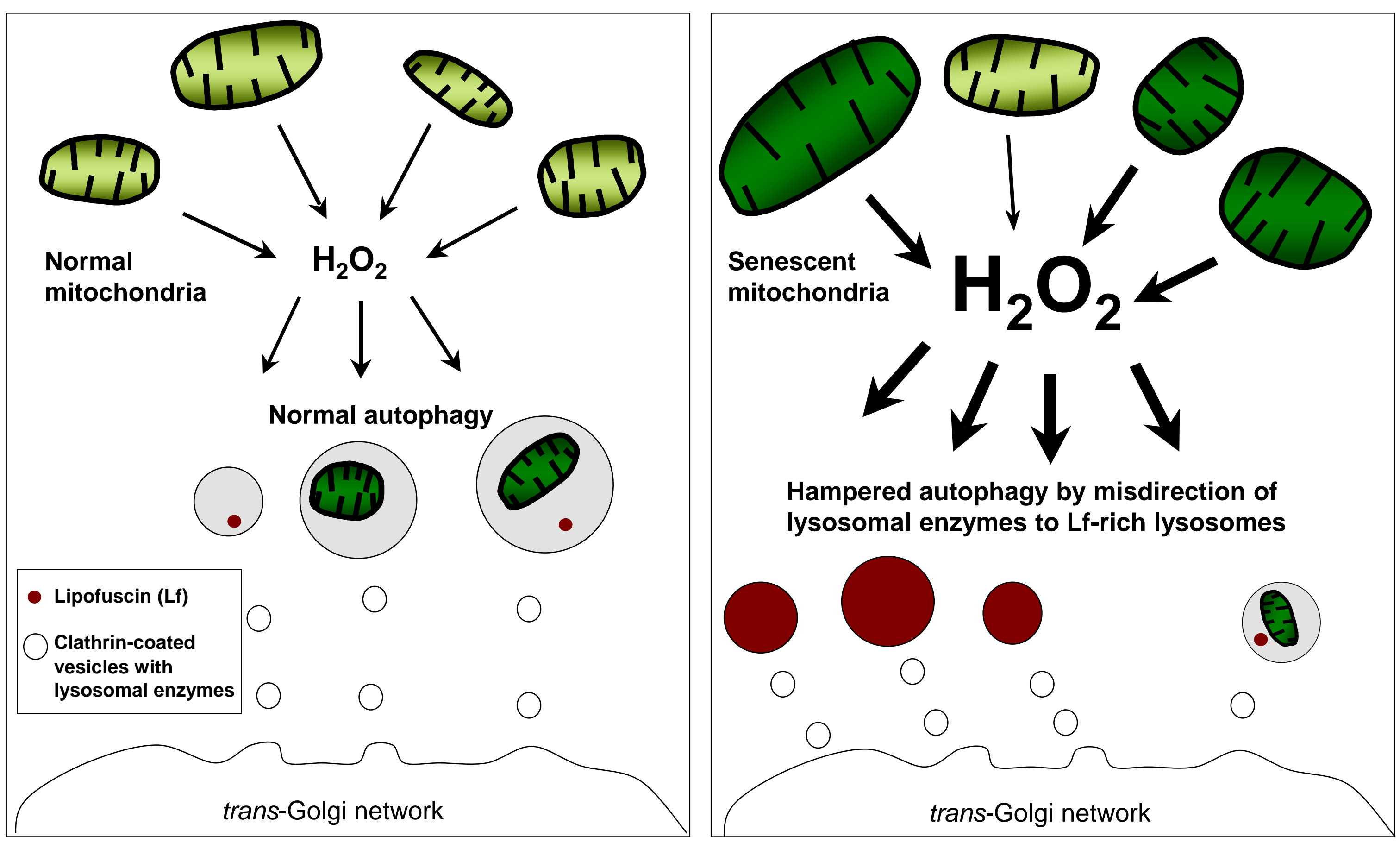


\begin{tabular}{ll}
\hline Protein & Function \\
\hline Divalent metal transporter 1 (DMT1) & $\mathrm{Fe}^{2+}$ membrane transporter \\
\hline Ferrireductase & Reduction of Fe ${ }^{3+}$ to $\mathrm{Fe}^{2+}$ \\
Ferritin & Iron storage protein \\
\hline Ferroportin & $\mathrm{Fe}^{2+}$ exporter \\
\hline Heme carrier protein (HCP) & Heme transport protein \\
Heme oxygenase 1 (Hmox-1) & Release of iron from heme \\
\hline Hepcidin & Negative regulator of ferroportin \\
Iron regulatory protein 1, 2 (IRP1, IRP2) & Iron sensors \\
Mitoferrin 1, 2 & Mitochondrial iron transporters \\
\hline Transferrin (Tf) & Fe \\
Transferrin receptor 1 (TfR1) & Binding of iron-loaded transferrin \\
\hline
\end{tabular}

Table 1: Overview of selected proteins and their function in iron metabolism 